\title{
Gla-rich protein is involved in the cross-talk between calcification and inflammation in osteoarthritis
}

\author{
Sofia Cavaco ${ }^{1}$ - Carla S. B. Viegas ${ }^{1,2}$ - Marta S. Rafael ${ }^{1}$ - Acácio Ramos ${ }^{3}$. \\ Joana Magalhães $^{4,5} \cdot$ Francisco J. Blanco $^{4} \cdot$ Cees Vermeer ${ }^{6} \cdot$ Dina C. Simes $^{1,2}$
}

Received: 5 July 2015/Revised: 25 August 2015/Accepted: 27 August 2015/Published online: 4 September 2015

(C) Springer Basel 2015

\begin{abstract}
Osteoarthritis (OA) is a whole-joint disease characterized by articular cartilage loss, tissue inflammation, abnormal bone formation and extracellular matrix (ECM) mineralization. Disease-modifying treatments are not yet available and a better understanding of osteoarthritis pathophysiology should lead to the discovery of more effective treatments. Gla-rich protein (GRP) has been proposed to act as a mineralization inhibitor and was recently shown to be associated with OA in vivo. Here, we further investigated the association of GRP with OA mineralization-inflammation processes. Using a synoviocyte and chondrocyte OA cell system, we showed that GRP expression was up-regulated following cell differentiation throughout ECM calcification, and that inflammatory
\end{abstract}

Electronic supplementary material The online version of this article (doi:10.1007/s00018-015-2033-9) contains supplementary material, which is available to authorized users.

Dina C. Simes

dsimes@ualg.pt

1 Centre of Marine Sciences (CCMAR), University of Algarve, Campus de Gambelas, 8005-139 Faro, Portugal

2 GenoGla Diagnostics, Centre of Marine Sciences (CCMAR), University of Algarve, Faro, Portugal

3 Department of Orthopedics and Traumatology, Algarve Medical Centre (CHAlgarve), Faro, Portugal

4 Grupo de Bioingeniería Tisular y Terapia Celular (GBTTCCHUAC), Servicio de Reumatología, Instituto de Investigación Biomédica de A Coruña (INIBIC), Complejo Hospitalario Universitario de A Coruña (CHUAC), Sergas, Universidad de A Coruña (UDC), A Coruña, Spain

5 Centro de Investigación Biomédica en Red de Bioingeniería, Biomateriales y Nanomedicina (CIBER-BBN), Madrid, Spain

6 VitaK, Maastricht University, Maastricht, The Netherlands stimulation with IL-1 $\beta$ results in an increased expression of COX2 and MMP13 and up-regulation of GRP. Importantly, while treatment of articular cells with $\gamma$ carboxylated GRP inhibited ECM calcification, treatment with either GRP or GRP-coated basic calcium phosphate (BCP) crystals resulted in the down-regulation of inflammatory cytokines and mediators of inflammation, independently of its $\gamma$-carboxylation status. Our results strengthen the calcification inhibitory function of GRP and strongly suggest GRP as a novel anti-inflammatory agent, with potential beneficial effects on the main processes responsible for osteoarthritis progression. In conclusion, GRP is a strong candidate target to develop new therapeutic approaches.

Keywords Osteoarthritis · Gla-rich protein . ECM mineralization · Gamma-carboxylated GRP . Inflammation

\section{Introduction}

Osteoarthritis (OA) is the leading form of degenerative joint diseases [1] characterized by progressive loss of articular cartilage, abnormal bone formation, tissue inflammation and synovial proliferation, culminating in pain, loss of joint function and disability [2,3]. At the cellular level, OA results from abnormal chondrocyte differentiation into a hypertrophic phenotype and impairment of the homeostatic balance between synthesis and degradation of their extracellular matrix (ECM). This phenotype is commonly associated with ECM mineralization that can result from basic calcium phosphate (BCP) crystals deposition [4] contributing to disease progression [5]. Crystal deposition in $\mathrm{OA}$ is not unique for cartilage and has also 
been reported in the synovial fluid and membrane, where it modulates inflammatory responses $[6,7]$. The prevailing theory is that proinflammatory and catabolic mediators, such as nitric oxide, cytokines, prostaglandins and matrix metalloproteinases (MMPs) [5, 7, 8], are released from cartilage into the synovial space, and that the presence of calcium crystals amplifies the production of such mediators, contributing to joint inflammation and cartilage degradation $[5,7]$.

Osteoarthritis prevention and treatment are still limited impelling the need to identify novel targets and biomarkers for prevention, therapeutics and prophylactic treatment [9]. An interesting candidate is vitamin $\mathrm{K}$, which is critical for preventing soft tissue mineralization [10, 11]. Moreover, vitamin $\mathrm{K}$ was also suggested as a protective agent against inflammation [12]. Vitamin $\mathrm{K}$ is an essential cofactor for the post-translational modification of vitamin K-dependent proteins (VKDPs), where specific glutamic acid (Glu) residues can be modified to calcium binding $\gamma$-carboxyglutamic acid (Gla) residues [13]. While subclinical vitamin $\mathrm{K}$ levels have been associated with an increased risk of $\mathrm{OA}$ development [14, 15], several VKDPs, such as matrix Gla protein (MGP), osteocalcin (OC), and recently Gla-rich protein (GRP), have been associated with the disease. Moreover, the presence of undercarboxylated OC in serum, resultant of vitamin $\mathrm{K}$ insufficiency, is considered as a risk marker for OA [16]. Importantly, impaired $\gamma$-carboxylation of MGP has been associated with increased mineralization of osteoarthritic cartilage [15], whereas also levels of undercarboxylated MGP in synovial fluid and serum were recently suggested as a potential inflammatory marker of arthritis [17].

GRP is the newest member of the VKDP family. It was first identified in sturgeon calcified cartilage and characterized by the presence of 15 putative Gla residues in man [18], but its function and molecular mechanisms of action remain to be further clarified. GRP has been suggested to act as a modulator of calcium availability in the ECM [19, 20], and an inhibitor of calcification in the cardiovascular system [21]. However, conflicting data, particularly associated to its function in mouse skeletal tissues, reinforce the need for additional characterization of GRP potential association to human pathological conditions such as OA. While GRP-deficient mice did not reveal evident phenotypic alterations in bone and cartilage [22], zebrafish knockdown studies highlighted the essential role of GRP in skeletal development and calcification [23]. Although GRP has been shown to function as a negative regulator of osteogenic differentiation [24, 25] and to be down-regulated by bone morphogenetic protein 2 (BMP-2) in chondrogenic cells [24], recent data suggested that GRP is up-regulated by both runt-related transcription factor 2 (Runx2) and osterix (Osx) stimulating osteoblast differentiation and nodule formation [26]. Our previous studies revealed a differential pattern of GRP gene expression and protein accumulation between control and osteoarthritic human articular cartilage and synovial membrane tissues. Furthermore, we verified that GRP accumulation was not restricted to sites of ectopic calcification [27], suggesting the involvement of this VKDP in cell-mediated processes other than ECM calcification in OA.

In this context, and to further understand the relevance of GRP for OA etiology, we used an in vitro cell system to study the relationship between GRP and the mineralization and inflammatory processes involved in OA development and progression. Our results demonstrate the involvement of GRP in calcification processes associated to OA-affected tissues, supporting a previously proposed role for GRP as a novel biomarker for calcification-related diseases. Moreover, we describe, for the first time, a new role for GRP in inflammatory events, and propose this VKDP as a novel factor linking the two main pathological processes responsible for $\mathrm{OA}$ development and progression.

\section{Materials and methods}

\section{Biological material and sample processing}

Knee articular cartilage and synovial membrane samples were obtained from osteoarthritic patients who had undergone arthroplasty surgeries. Tissues were collected in Dulbecco's Modified Eagle's Medium (DMEM, Invitrogen, Carlsbad, CA, USA) for cell culture preparation and in formalin for histological processing, followed by paraffin embedding as described [28]. This study was approved by the ethics committees of the hospitals involved, and written informed consent was obtained from all the participants.

\section{Cell culture development and maintenance}

Tissues, both articular cartilage and synovial membrane, were digested overnight with $2 \mathrm{mg} / \mathrm{mL}$ collagenase in DMEM at room temperature (RT). Fragments were washed three times with DMEM, placed in 24-well plates, and cultured in the same medium supplemented with $1 \%(\mathrm{v} / \mathrm{v})$ penicillin-streptomycin, $1 \mathrm{mM}$ L-glutamine and $10 \%(\mathrm{v} /$ v) fetal bovine serum (FBS), at $37{ }^{\circ} \mathrm{C}$ in a humidified atmosphere with $5 \% \mathrm{CO}_{2}$. OA-derived chondrocytes (OAHAC, osteoarthritic human articular chondrocytes) and synoviocytes (OA-HFLS, osteoarthritic human fibroblastlike synoviocytes) were allowed to migrate from fragments and adhere to wells for approximately 2 weeks, then collected using trypsin solution (Invitrogen) for cell passage, and placed into new plate dishes with fresh media. Cultures 
were routinely sub-cultured $(1: 2)$ at early confluence by trypsinization. Cellular proliferation measurements indicated higher growth performance using advanced DMEM (Invitrogen) supplemented with $1 \%$ (v/v) penicillinstreptomycin, $1 \mathrm{mM}$ L-glutamine and $10 \%$ (v/v) FBS when compared with DMEM. Therefore, advanced DMEM was used throughout the study, in all cell lines. Cells used in the experiments were between passages 4 and 14 .

Control primary chondrocytes (NHAC, Lonza, Visp, Switzerland) and synoviocytes (HFLS, ECACC, SigmaAldrich, St. Louis, MO, USA) were commercially obtained. A second set of OA and control-derived primary chondrocytes cultures (OAC and NC, respectively) and primary synoviocytes cultures (SOAR and SNR, respectively) were obtained using well-defined methodology [29, 30], and used to confirm the results obtained with of the first set of cells.

\section{Cellular proliferation measurement}

Cells were seeded in 96-well plates at $2 \times 10^{4}$ cells/well and cultured in DMEM and advanced DMEM supplemented with $1 \%(\mathrm{v} / \mathrm{v})$ penicillin-streptomycin, $1 \mathrm{mM} \mathrm{L}-$ glutamine and $10 \%$ (v/v) FBS and both culture conditions were analyzed for cell viability at appropriate times using the CellTiter 96 cell proliferation assay (Promega, Madison, WI, USA), following manufacturer's instructions. Cell viability of cultures supplemented with $5.4 \mathrm{mM} \mathrm{CaCl}$, $500 \mathrm{ng} / \mathrm{mL}$ of sturgeon cGRP or human recombinant ucGRP [20], $5 \mathrm{ng} / \mathrm{mL}$ of interleukin $1 \beta$ (IL-1 $\beta$ ) or $100 \mu \mathrm{g} /$ $\mathrm{mL}$ of BCP crystals (prepared as described below) was also determined using the same procedure.

\section{RNA extraction, cDNA amplification and quantitative real-time PCR (qPCR)}

Total RNA was isolated from cell cultures as described by Chomczynski and Sacchi [31]. RNA concentration was determined by spectrophotometry at $260 \mathrm{~nm}$ and quality evaluated by agarose-denaturing gel electrophoresis. Five hundred ng of total RNA was treated with DNase RQ-I (Promega) and reverse transcribed using Moloney-murine leukemia virus reverse transcriptase (MMLV-RT, Invitrogen), RNase Out (Invitrogen), and an oligo(dT) adapter (ACGCGTCGACCTCGAGATCGATG(T) $)_{13}$ ), according to manufacturer's recommendations.

Quantitative real-time PCR reactions were performed using the StepOne system (Life Technologies, Carlsbad, CA, USA), SsoFast Eva Green Supermix (Bio-Rad, Richmond, CA, USA), $300 \mathrm{nM}$ of forward and reverse genespecific primers (final concentration) for genes of interest (Online Resource 1) and a 1:5 dilution of reverse-transcribed RNA reaction mixture. The following PCR conditions were used: initial denaturation/enzyme activation step at $95{ }^{\circ} \mathrm{C}$ for $5 \mathrm{~min}, 50$ cycles of amplification (one cycle is $30 \mathrm{~s}$ at $95^{\circ} \mathrm{C}$ and $15 \mathrm{~s}$ at $66^{\circ} \mathrm{C}$ ); $18 \mathrm{~S}$ was used as a housekeeping gene to normalize expression.

\section{Immunofluorescence and immunohistochemistry}

Immunofluorescence (IF) was performed in sub-confluent cultures, seeded the previous day. Cells were washed with PBS and fixed for $10 \mathrm{~min}$ in $4 \%$ (v/v) paraformaldehyde. Fixed cells were incubated at RT for $1 \mathrm{~h}$ with CTerm-GRP (10 $\mu \mathrm{g} / \mathrm{mL}$, GenoGla Diagnostics, Faro, Portugal), mouse monoclonal cGRP $(10 \mu \mathrm{g} / \mathrm{mL}$, GenoGla Diagnostics) or mouse monoclonal ucGRP [20] $(7.3 \mu \mathrm{g} / \mathrm{mL}$, VitaK BV, Maastricht, The Netherlands) primary antibodies, followed by incubation for $1 \mathrm{~h}$, at RT with Alexa488 or Alexa594 labeled secondary antibodies (Invitrogen), respectively. Fluorescence images were obtained using an Axio Imager Z2 microscope (Zeiss, Jena, Germany) equipped with a digital camera and AxioVision imaging software. Final images were processed using Image J Version $1.41 \mathrm{~m}$.

Immunohistochemistry (IHC) was performed in paraffin tissue sections of osteoarthritic synovial membrane as described [32]. Antigen retrieval was performed by boiling tissue sections in $0.2 \%(\mathrm{v} / \mathrm{v})$ citric acid $\mathrm{pH}$ 6.0, followed by endogenous peroxidase and nonspecific antibody blocking and incubations with CTerm-GRP $(5 \mu \mathrm{g} / \mathrm{mL})$ or mouse monoclonal cluster of differentiation 45 (CD45, $2 \mu \mathrm{g} / \mathrm{mL}$, Santa Cruz Biotechnology) primary antibodies. Peroxidase activity was detected using the respective peroxidase-conjugated secondary antibodies (Sigma-Aldrich) and ImmPACT NovaRED substrate kit (Vector laboratories Ltd., Peterborough, UK). Sections were counterstained with hematoxylin.

\section{ECM mineralization assay}

To induce mineralization of the ECM, confluent cultures grown in advanced DMEM were supplemented with $\mathrm{CaCl}_{2}$ to a final calcium concentration of $5.4 \mathrm{mM}$. The experiment was performed during 3 weeks with media changes twice a week and each week set as an experimental time point (T0-T3). Mineral content was detected by von Kossa staining as described [33]. Formation of mineralized nodules in the ECM was observed under a Motic AE 31 inverted light microscope.

To analyze the effect of GRP on mineralization, confluent chondrocytes and synoviocytes were grown for 3 weeks in advanced DMEM under mineralizing conditions supplemented with $500 \mathrm{ng} / \mathrm{mL}$ of cGRP or ucGRP and compared with respective controls. At appropriate times, calcium/protein ratios were determined, as described below. 


\section{Calcium and total protein quantification}

At appropriate times, cell cultures grown in control or mineralizing conditions were washed twice with PBS and mineral was dissolved overnight with $1 \mathrm{M} \mathrm{HCl}$, at $4{ }^{\circ} \mathrm{C}$. ECM calcium concentration was then determined using a commercially available kit (Calcium assay CA-590, Randox, Co. Antrim, UK). Equimolar amounts of $\mathrm{NaOH}$ containing $5 \%(\mathrm{w} / \mathrm{v})$ SDS were then used to neutralize the remaining $\mathrm{HCl}$-mineral phase and determine total protein concentration using the micro BCA protein assay kit (Thermo Scientific, Waltham, MA, USA). Results are thus presented as calcium/protein ratios.

\section{Inflammation assay}

Confluent chondrocytes and synoviocytes were cultured in advanced DMEM or supplemented with $500 \mathrm{ng} / \mathrm{mL}$ of cGRP, $500 \mathrm{ng} / \mathrm{mL}$ of ucGRP or $2 \mu \mathrm{M}$ dexamethasone (DXM) during $24 \mathrm{~h}$. Cells were washed twice with PBS and media were changed for advanced DMEM supplemented with $5 \mathrm{ng} / \mathrm{mL}$ of IL-1 $\beta$ for $72 \mathrm{~h}$. At appropriate times, cell media were collected for prostaglandin E2 (PGE2) quantification and cells washed twice with PBS for RNA extraction. PGE2 measurement was achieved using an available ELISA kit (Thermo Scientific) following manufacture's protocol.

\section{Protein mineral complex (PMC) assay}

BCP crystals were produced based on a previously described procedure, and the resulting crystals were washed three times with Milli-Q water and reduce to fine particles by sonication (Vibra-cell apparatus, Sonics \& Materials, Inc., Newtown, MA, USA) [21, 34]. PMCs were prepared by incubating BCP crystals $(100 \mu \mathrm{g})$ in Milli-Q water for $30 \mathrm{~min}$ at $37{ }^{\circ} \mathrm{C}$ with approximately $500 \mathrm{ng}$ of cGRP or ucGRP [21]. Pellets containing PMCs or BCP crystals were added to confluent chondrocytes and synoviocytes and assayed for $72 \mathrm{~h}$ (controls consist of culture medium only). At appropriate times, cells were washed twice with PBS prior to RNA extraction and cell media were collected for PGE2 measurement as previously described.

\section{Statistical analysis}

Data are presented as mean $(n>2) \pm$ standard error. Ordinary one-way ANOVA was used for comparisons within the same group. Multiple $t$ tests were used for comparison between two groups. For two groups submitted to a variable, significance was determined using two-way ANOVA and multiple comparisons were achieved with the
Tukey's test. Statistical significance was defined as $P \leq 0.05$ (*) $^{*} P \leq 0.005$ (**) $^{*}$ and $P \leq 0.0005$ (***). $^{*}$

\section{Results}

\section{GRP and genes involved in the $\gamma$-carboxylation} machinery are associated with osteoarthritis

The association of GRP with OA was analyzed on chondrocyte and synoviocyte primary cell cultures, the two main cell types involved in OA pathology. Human articular chondrocytes and fibroblast-like synoviocytes, either control (NHAC and HFLS, respectively) or derived from OA patients (OA-HAC and OA-HFLS, respectively), were characterized by gene expression profiling of differentiation and known OA-related markers, and correlated with the expression of GRP, MGP, and genes related to $\gamma$-carboxylation processing. The obtained results showed higher levels of OC, cartilage oligomeric matrix protein (COMP) and collagen type $\mathrm{X}$ (Col10a1), and lower levels of collagen type II (Col2a1) in OA-HAC cells (Fig. 1a), confirming an osteoarthritic chondrocyte phenotype. Also, OA-HFLS cells, exhibited higher levels of the OA-associated gene markers OC, MMP13 and CD68, and lower vimentin expression (Fig. 1a).

GRP and MGP were found to be up-regulated in both OA-derived cultures, OA-HAC and OA-HFLS, while $\gamma$ carboxylase (GGCX) and vitamin $\mathrm{K}$ epoxide reductase (VKOR) were shown to be expressed at lower levels than in control-derived cells (Fig. 1b), suggesting an increased production of VKDPs, but an impaired $\gamma$-carboxylation capacity in OA-derived cells. To access GRP $\gamma$-carboxylation status, the protein accumulation pattern was analyzed in OA and control cells by IF using the conformation-specific monoclonal antibodies cGRP and ucGRP, and the polyclonal CTerm-GRP recognizing total GRP (Fig. 2). In concordance with previously reported data from osteoarthritic cartilage and synovial membrane tissue samples [27], both cGRP and ucGRP were detected in pathological and control chondrocyte cells, while only ucGRP was found associated with the OA-HFLS cells.

Overall, the results indicate that OA-derived cells showing osteoarthritic gene expression patterns have GRP up-regulation and indications of a reduced $\gamma$-carboxylation capacity.

\section{Calcification and cell differentiation in $\mathrm{OA}$ are correlated with GRP expression}

The calcification capacity of both NHAC/OA-HAC and HFLS/OA-HFLS cells was assessed by von Kossa staining (Fig. 3a) and by calcium quantification of the mineral 
(a)
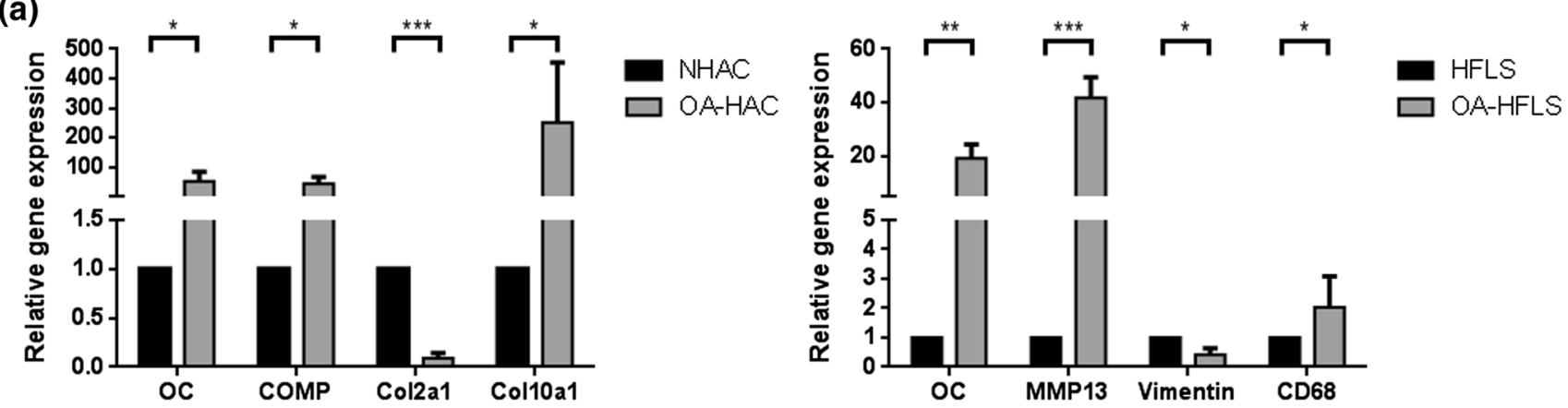

(b)
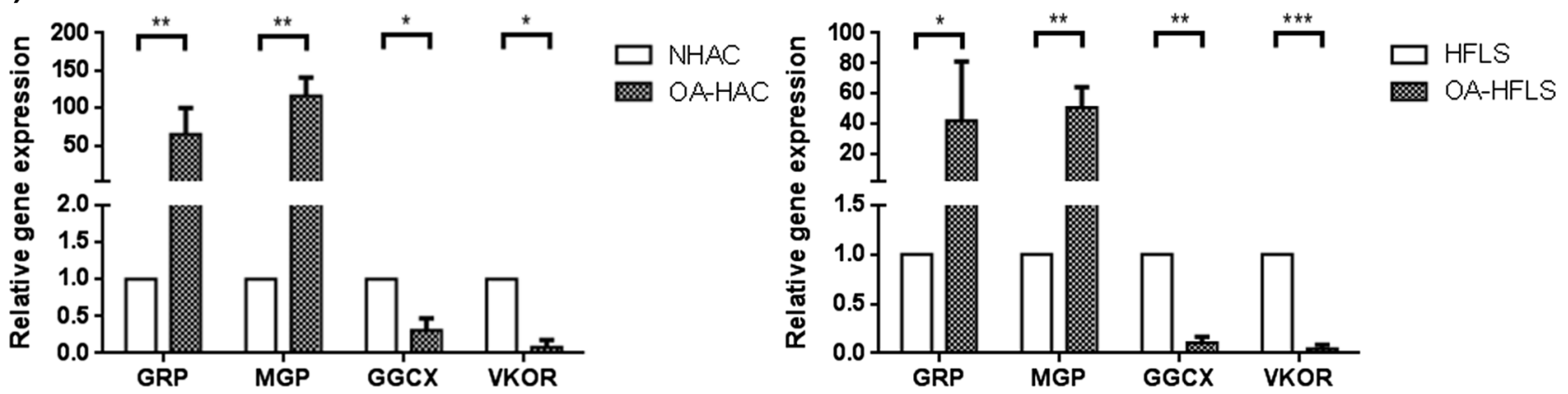

Fig. 1 Characterization of control and osteoarthritic-derived (OA) chondrocyte and synoviocyte cell cultures through gene expression patterns determined by qPCR. a Expression of OA (OC, COMP and MMP13) and differentiation (Cola2a1, Cola10a1, CD68 and vimentin) gene markers in control (NHAC and HFLS) and OA-derived (OA-HAC and OA-HFLS) chondrocytes and synoviocytes.

deposited in the ECM (Fig. 3b). The results showed that all cell cultures were able to mineralize their ECM, although after the 3 weeks of treatment higher calcium levels and mineral deposition were found in chondrocyte-derived cultures when compared to synoviocytes (Fig. 3a, b, T3). Significant differences in calcium quantification between $\mathrm{OA}$ and control chondrocytes were evident at week $1(T 1)$, although during subsequent weeks the differences gradually disappeared.

The expression patterns of gene markers for cell differentiation and mineralization were simultaneously investigated, in control and OA-derived primary cells to determine their correlation with calcification. After the first week of treatment ( $T 1)$, OA-HAC cells showed higher expression levels of GRP, MGP, OC, Osx and Col10a1, and lower levels of Col2a1, compared to control NHAC cells (Fig. 4a). The progressive down-regulation of Col2a1 in parallel with the up-regulation of Col10a1, Osx and OC throughout the treatment in both cultures is consistent with differentiation occurring in chondrocytes towards a hypertrophic phenotype and ECM calcification.

The most significant differences between control and OA-derived cells were observed at $T 1$, suggesting that, under calcification stimulating conditions the already altered phenotype of primary OA-derived cells induces a

b Expression of VKDP-related genes (GRP, MGP, GGCX and VKOR) in control and OA-derived chondrocytes and synoviocytes. Values are relative to a reference sample (control cell culture) set to 1 . All experiments were repeated at least three times. Multiple $t$ tests were performed. Statistical significance was defined as $P \leq 0.05\left(^{*}\right)$, $P \leq 0.005(* *)$ and $P \leq 0.0005(* * *)$

faster response. However, at $T 3$ most of the gene markers were found similarly expressed, in concordance with the similar levels of calcification obtained for both cultures (Fig. 3b). Notably, levels and patterns of GRP and Osx gene expression were found similarly up-regulated in OAderived chondrocytes, throughout mineralization treatment, with higher levels in OA-derived cells at all-time points. In synoviocytes, vimentin down-regulation and CD68 upregulation were observed during induced calcification, in both OA-derived and control cells; this is suggestive for a phenotypic change from fibroblast-like synoviocytes towards a macrophage lineage, while GRP, MGP, OC and osteopontin (OPN) were gradually up-regulated throughout mineralization, with only minor differences observed between OA-derived and control cells (Fig. 4b).

\section{Carboxylated GRP is able to reduce mineral deposition in articular cells ECM}

To determine the direct effect of GRP in ECM mineralization of chondrocytes and synoviocytes, and further unveil the relevance of its $\gamma$-carboxylation status, cells cultured under control and mineralizing conditions were supplemented with ucGRP or cGRP. Cell proliferation assays were performed for both GRP protein forms to 

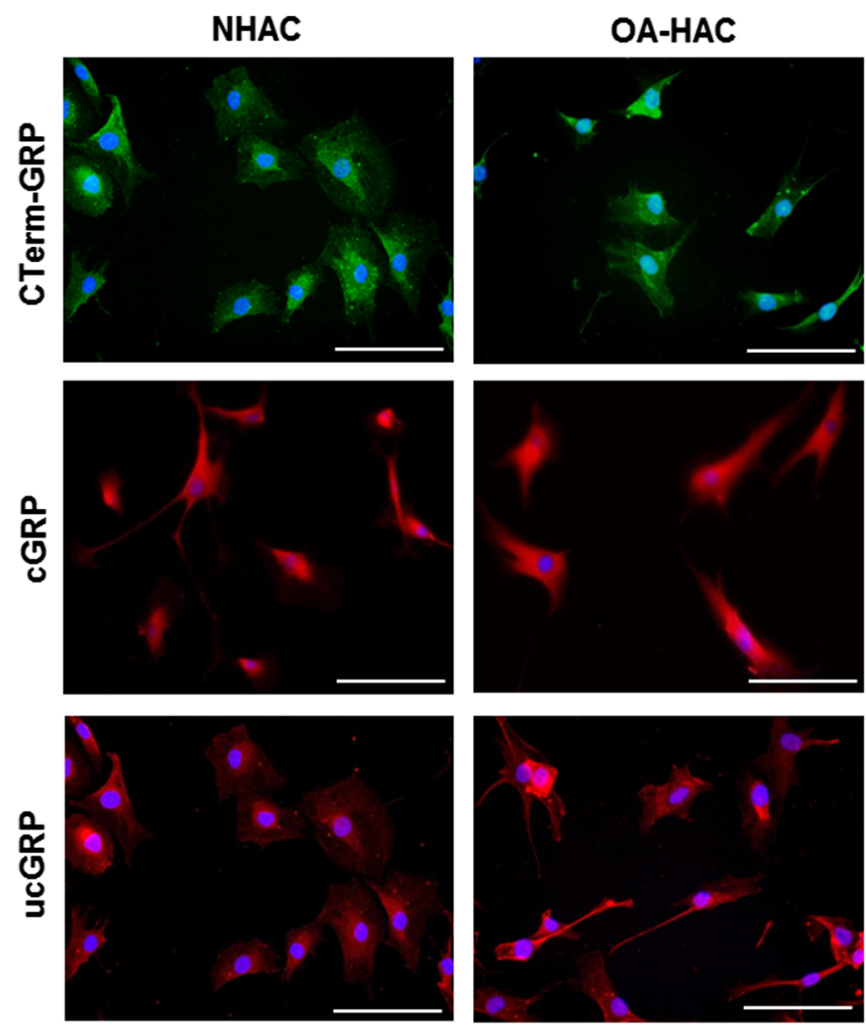

Fig. 2 Accumulation patterns of GRP protein forms in both control (NHAC and HFLS) and OA (OA-HAC and OA-HFLS)-derived chondrocytes and synoviocytes. Immunofluorescence imaging was obtained for total GRP (CTerm-GRP), $\gamma$-carboxylated (cGRP) and

confirm that the treatment was not cytotoxic (data not shown). The results showed that the addition of cGRP significantly decreased mineral deposition after 3 weeks of treatment, in both control (Fig. 5) or OA-derived (results not shown) chondrocytes and synoviocytes, while no effect was observed with ucGRP treatment.

\section{GRP is associated with inflammatory events in OA}

To study the interplay between mineralization and inflammatory events in OA, the inflammatory response of chondrocytes and synoviocytes under mineralization conditions was determined by analyzing the expression patterns of inflammation markers. Increased expression of COX2 and MMP13, throughout the time course indicated that a mineralization stimulus is able to trigger the inflammatory response in both cells systems (Fig. 6a). Since in this model, GRP was also found to be up-regulated with mineralization treatment (Fig. 4), we have further studied the possible relation between GRP and inflammation by inducing chondrocytes and synoviocytes with an inflammatory stimulus and evaluating GRP expression pattern. A sharp rise in GRP gene expression concomitant with an increase in COX2 and MMP13 expression was obtained at $3 \mathrm{~h}$ after $\mathrm{IL}-1 \beta$
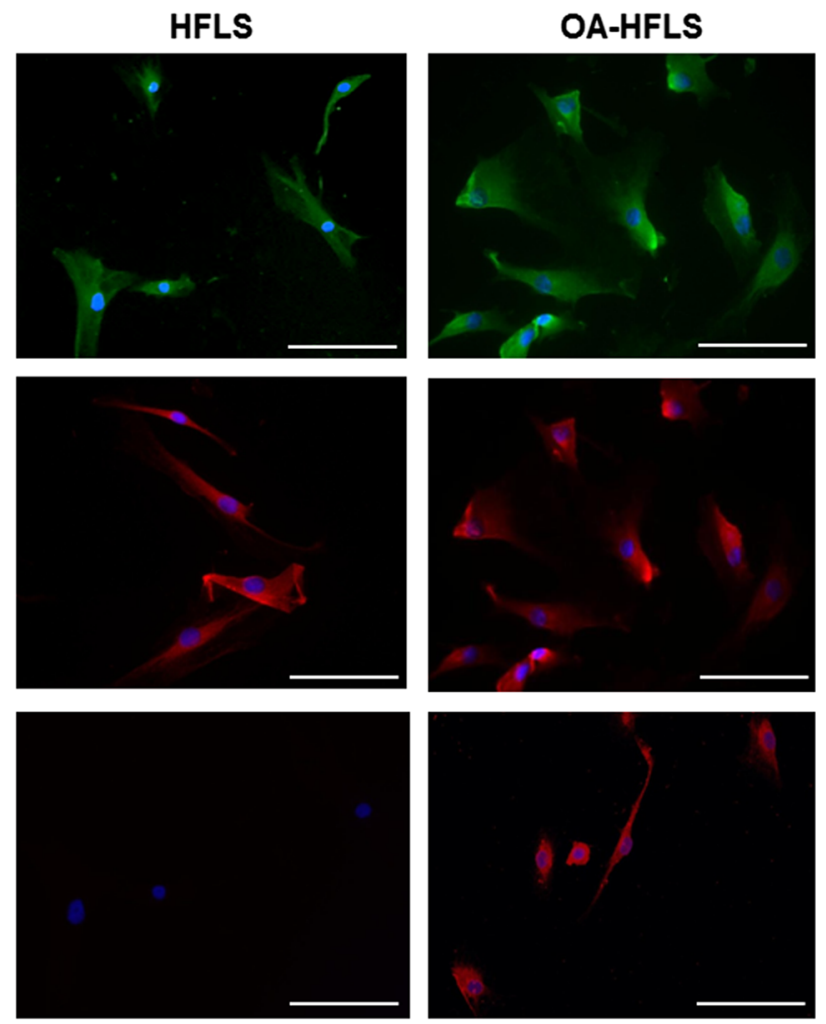

undercarboxylated GRP (ucGRP) protein forms using specific antibodies. Cell nuclei were stained with DAPI; scale bar represents $100 \mu \mathrm{m}$. All experiments were repeated at least twice

treatment (Fig. 6b). From 6 to $72 \mathrm{~h}$ of stimulation, the expression of GRP and inflammatory gene markers had progressively decreased until control levels. To evaluate the association of GRP with inflammation in vivo, the presence of GRP in osteoarthritic synovial membrane was determined by IHC and the results showed co-localization of GRP with CD45 positive cells, indicative of leucocytes (Fig. 6c-f).

\section{GRP is a novel factor in the cross-talk}

\section{between calcification and inflammation processes}

Since BCP crystals deposition has been associated with inflammatory responses in OA, and GRP binding capacity to calcium crystals has been previously reported [21], chondrocytes and synoviocytes were treated with BCP crystals and BCP crystals coated with either cGRP/ucGRP (PMCs), during $72 \mathrm{~h}$, to evaluate the inflammatory response. Up-regulation of COX2 and MMP13 expression in BCP-treated cells confirmed the inflammatory response mediated by BCP crystals, both in synoviocytes and chondrocytes cell systems, while treatment of cells with non-cytotoxic doses of PMCs, containing either cGRP or ucGRP, resulted in decreased COX2 and MMP13 expression (Fig. 7a). A corresponding significant reduction of 
(a)
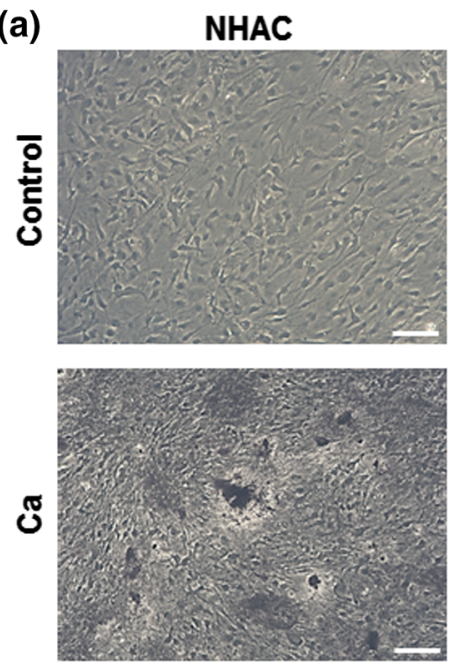

OA-HAC
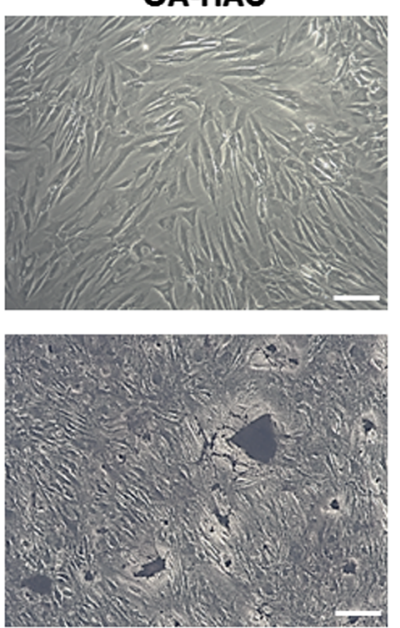

HFLS
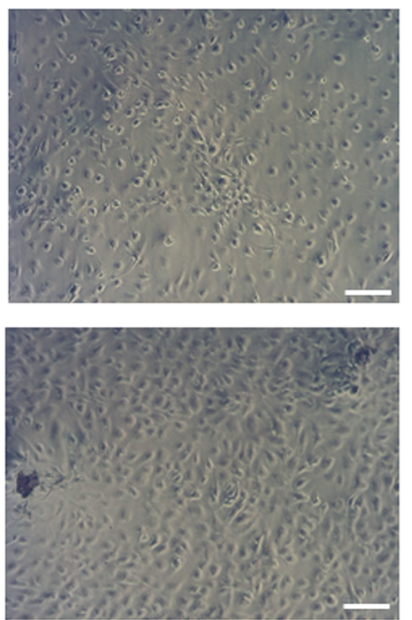

OA-HFLS
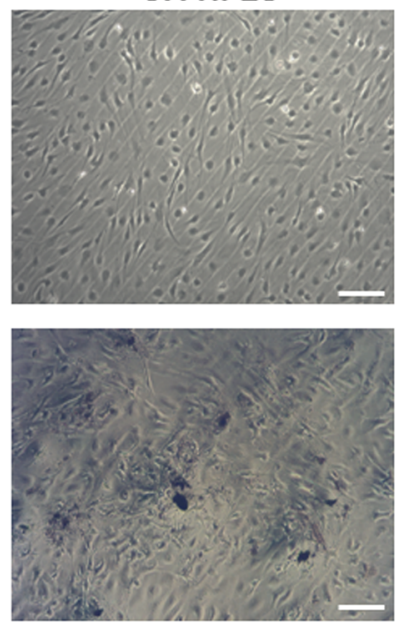

(b)

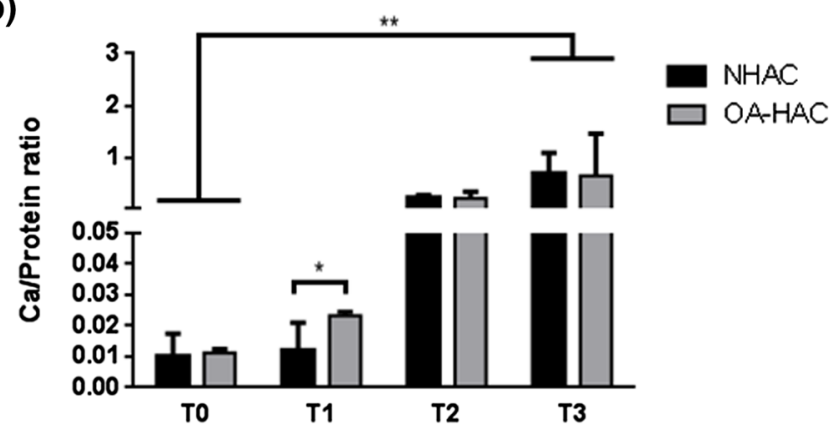

Fig. 3 In vitro ECM mineralization of control and OA-derived chondrocytes and synoviocytes (NHAC and OA-HAC, and HFLS and OA-HFLS, respectively). a Representative von Kossa staining at week 3 (T3) in control or induced mineralizing conditions with $5.4 \mathrm{mM} \mathrm{CaCl}_{2}(\mathrm{Ca})$. Scale bar represents $100 \mu \mathrm{m}$. b Mineralization

PGE2 accumulation in cell media was detected after $72 \mathrm{~h}$ of treatment with PMCs, when compared with cells treated with BCP crystals (Fig. 7b). Altogether, our results showed that GRP coating significantly diminished the inflammatory reaction associated with BCPs, and point GRP as a new mediator factor linking mineralization and inflammatory processes.

\section{GRP acts as an anti-inflammatory agent in osteoarthritis}

To determine if GRP had a direct effect on inflammatory processes and if this response was dependent of its $\gamma$-carboxylated state, chondrocytes and synoviocytes, stimulated with IL-1 $\beta$, were pre-treated with ucGRP/cGRP or DXM, the latter used as a control anti-inflammatory agent. In both cell systems stimulated with IL-1 $\beta$, the treatment with either ucGRP/cGRP, resulted in significant lower levels of COX2 and MMP13 expression relative to non-treated cells (Fig. 8a), indicating an anti-inflammatory effect of GRP. To further confirm these results, PGE2 accumulation in cell

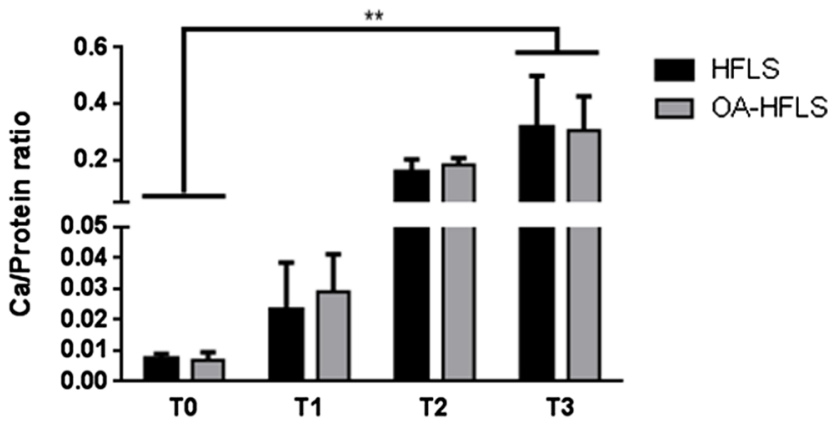

rate was determined every week (T0-T3) through calcium quantification normalized to protein levels. Data are representative of three independent experiments. Two-way Anova and multiple comparisons were achieved with the Tukey's test. Statistical significance was defined as $P \leq 0.05(*)$ and $P \leq 0.005(* *)$

media after $24 \mathrm{~h}$ of pre-treatment with cGRP and ucGRP (Fig. 8b) was measured, and the results showed lower levels of PGE2 in media of cells pre-treated with both protein forms relative to non-treated cells. Moreover, a similar anti-inflammatory effect was observed in OA-HAC and OA-HFLS cells. Notably, the ucGRP/cGRP effects on COX2 and MMP13 expression were comparable with levels obtained after $3 \mathrm{~h}$ of IL- $1 \beta$ stimulation in cells pretreated with DXM, particularly in chondrocytes (Online Resource 2). The 3-h stimulation period corresponds with the inflammatory peak response. These results strongly suggest that GRP might be a powerful anti-inflammatory agent in OA that can exert its function independent of its $\gamma$ carboxylation status.

\section{Discussion}

In this study, we demonstrate for the first time the involvement of GRP, the most recently discovered VKDP, in the two major molecular processes affecting 

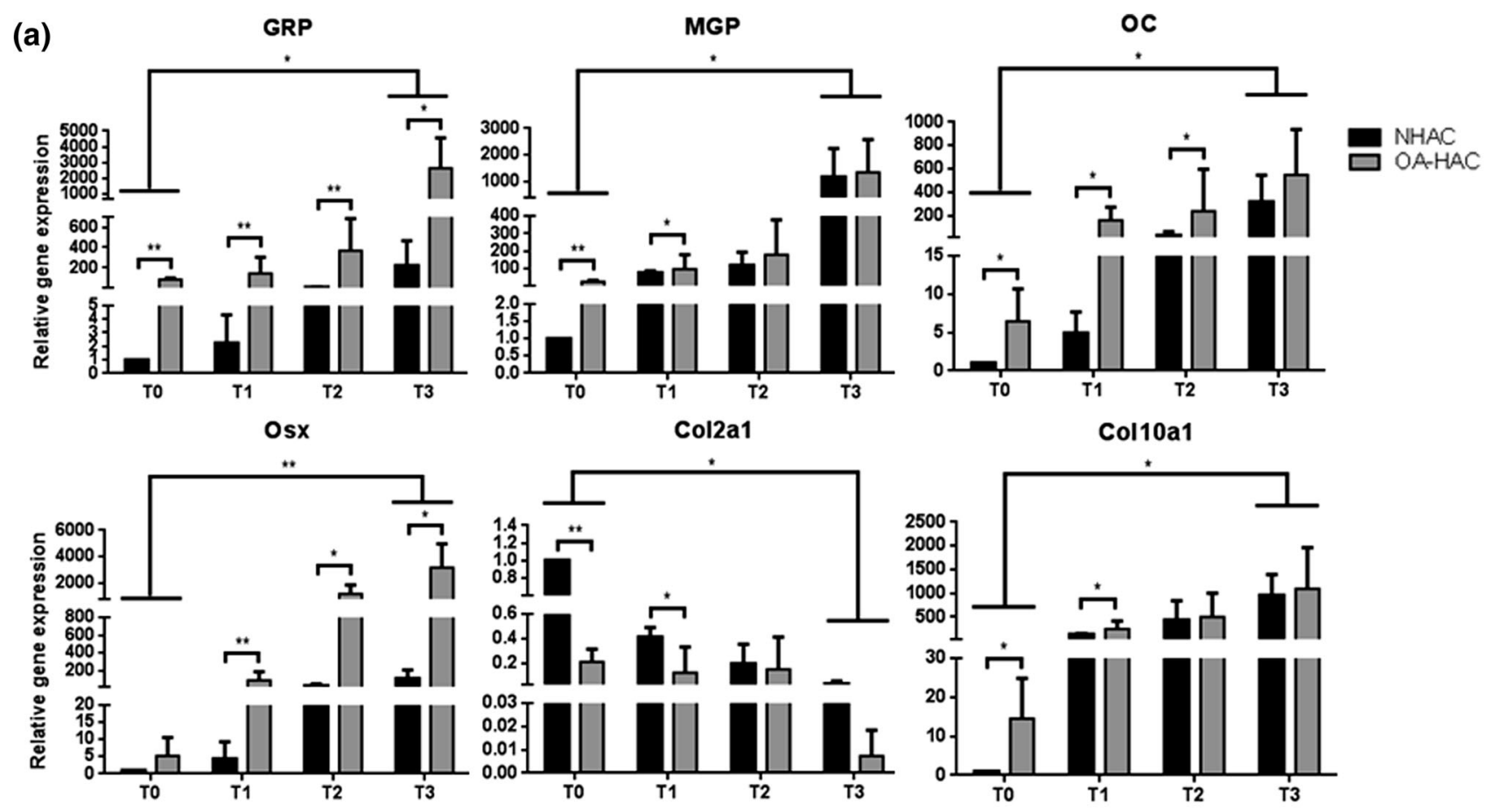

(b)
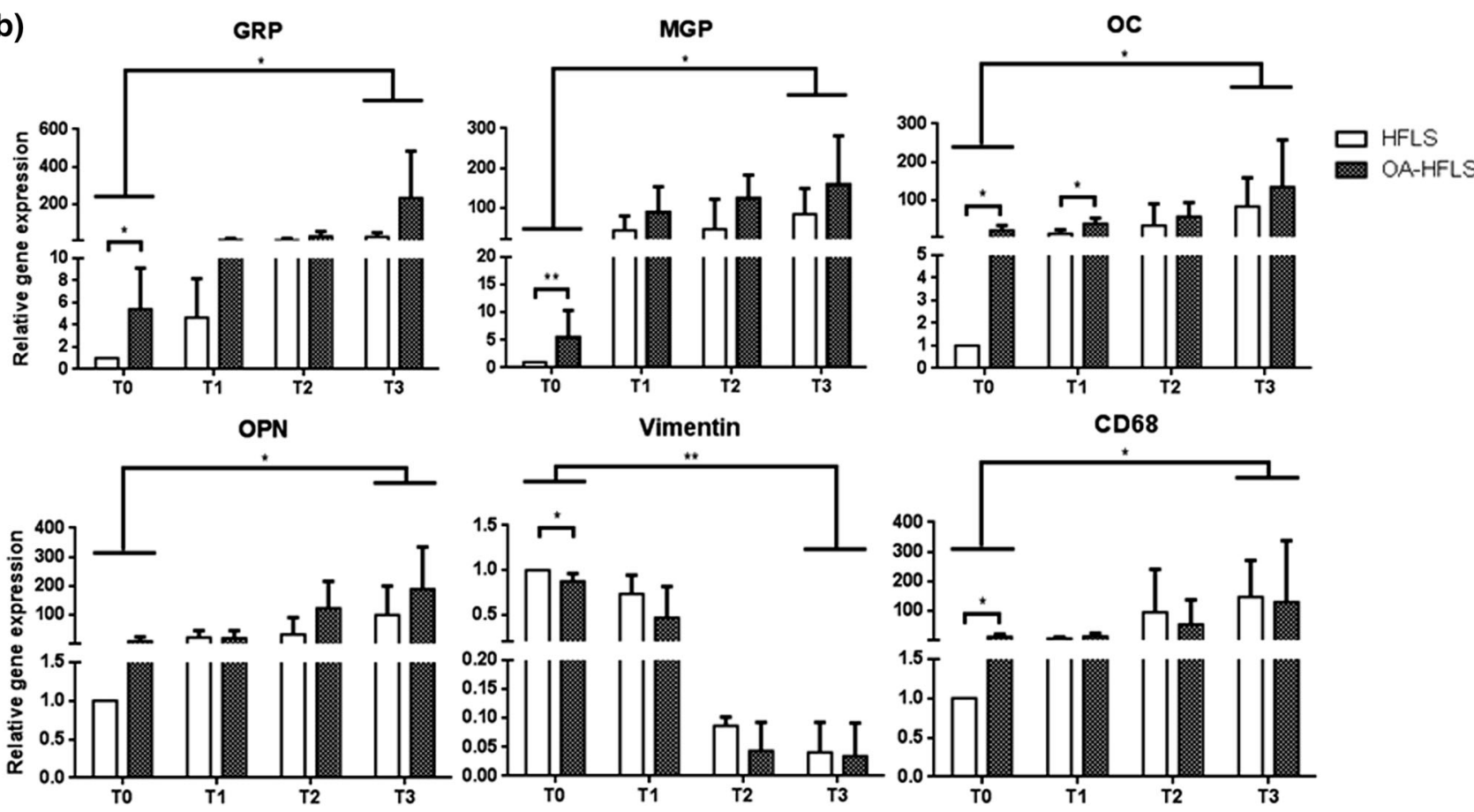

Fig. 4 Association of GRP with calcification and cell differentiation in osteoarthritis. a Gene expression patterns of GRP, mineralization (MGP, OC and Osx) and differentiation (Col2a1 and Col10a1) markers during induced mineralization of chondrocytes (NHAC and OA-HAC). b Gene expression patterns of GRP, mineralization (MGP, OC and OPN) and differentiation (vimentin and CD68) markers during induced mineralization of synoviocytes (HFLS and OA-

osteoarthritis: mineralization and inflammation of articular tissue. GRP appears to be functioning as an ECM mineralization inhibitor and as an anti-inflammatory agent, both
HFLS). Gene expression was determined every week during 3 weeks (T0-T3). Gene expression values are relative to the reference sample (control cell culture) and set to 1. Data are representative of three independent experiments. Two-way Anova and multiple comparisons were achieved with the Tukey's test. Statistical significance was defined as $P \leq 0.05\left(^{*}\right)$ and $P \leq 0.005(* *)$

on chondrocytes and synoviocytes, the two main articular cell types. Moreover, while GRP $\gamma$-carboxylation was shown to be essential for its calcification inhibitor effect, it 


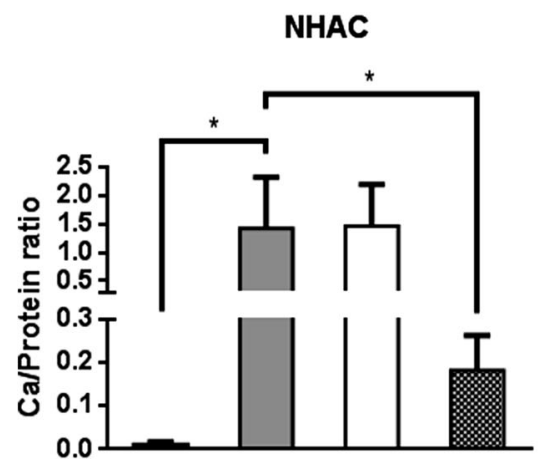

Fig. 5 Effect of GRP in ECM mineral deposition in chondrocytes and synoviocytes. Mineralization rate was determined by calcium measurement (normalized to protein levels) after 3 weeks of NHAC and HFLS cells treatment with $5.4 \mathrm{mM} \mathrm{CaCl}_{2}(\mathrm{Ca})$, or supplemented with $500 \mathrm{ng} / \mathrm{mL}$ of ucGRP $(\mathrm{Ca}+\mathrm{ucGRP})$ or cGRP $(\mathrm{Ca}+\mathrm{cGRP})$.

was apparently irrelevant for its anti-inflammatory action, pointing to differential roles for undercarboxylated and carboxylated GRP.

GRP gene expression was found to be up-regulated in OA-derived chondrocytes and synoviocytes, and was associated with higher levels of the calcification inhibitor MGP and OA-related gene markers such as OC, COMP and Col10a1. The results here obtained are in concordance with our previous studies with biological samples, where we showed an increase in GRP expression associated with OA [27], and also with the higher demand of calcification inhibitors, required to balance increased cell differentiation and ECM calcification occurring in OA [4]. Moreover, $\gamma$ carboxylated GRP was shown to decrease calcification in both chondrocytes and synoviocytes, and the increase in GRP expression accompanied cell differentiation towards ECM mineralization, in both cell systems. The up-regulation of GRP during osteochondrogenic differentiation, characterized by a decrease in Col2a1 and concomitant increase in Col10a1, was recently shown during osteogenic differentiation of MC3T3 cells, supporting the suggested up-regulation of GRP gene by Osx [26]. Nevertheless, previous studies have shown that GRP is repressed by BMP2, a protein known to be responsible for Osx upregulation during osteogenesis [24]. These controversial data emphasize that the molecular mechanism of GRP action requires further clarification. Moreover, while GRP was suggested to act as a stimulating factor in osteoblast differentiation and nodule formation [26], previous data have shown an impairment of osteogenic differentiation by GRP [24, 25]. None of these studies have taken into consideration the fact that GRP is a $\gamma$-carboxylated protein, and we have shown that although both forms, cGRP and ucGRP, have mineral-binding capacity, only cGRP is able to inhibit ECM calcification in the vascular system [21]. In concordance, GRP knockdown in zebrafish resulted in severe growth retardation and perturbance of skeletal development, while warfarin treatment mimicked the GRP knockdown phenotype, suggesting an essential role of $\gamma$ carboxylation for GRP function [23]. Our new data, using GRP media supplementation in chondrocyte and synoviocyte cell cultures, strengthen the proposed calcification inhibitory function of GRP and reinforce the importance of its $\gamma$-carboxylation status, probably acting by decreasing calcium availability in the local environment, or changing the dynamics of crystal growth [21]. Increased extracellular calcium levels have been shown to drive chondrocyte differentiation towards a mineralizing phenotype, while calcium depletion from culture media maintains a stable cellular phenotype [35]. GGCX and VKOR are two crucial enzymes involved in $\gamma$-carboxylation [13]. Remarkably, the increase of GRP and MGP expression in OA-derived cells was associated with a down-regulation of GGCX and VKOR genes, suggesting a reduced capacity of OA cells, and consequently a decrease in the $\gamma$-carboxylation of target proteins such as GRP and MGP. In fact, we have previously shown a predominance of ucGRP and ucMGP in biological OA samples [27]. Moreover, reduced vitamin $\mathrm{K}$-dependent $\gamma$-carboxylase activity has been reported in OA chondrocytes and correlated with (1) decreased $\gamma$ carboxylation of MGP and (2) increased matrix mineralization [36]. Although the triggers for articular cartilage calcification associated with OA are still not completely understood, dysregulation of mineral metabolism such as calcium and phosphate and an imbalance in the production of mineralization inhibitors are crucial factors favoring cartilage calcification and deposition of calcium-containing crystals, such as BCPs. It should be noted that these factors that trigger articular calcification are important to avoid chondrocyte phenotype alterations such as hypertrophic differentiation, apoptosis, as well as altered responses to inflammatory cytokines and mediators of inflammation 
(a)

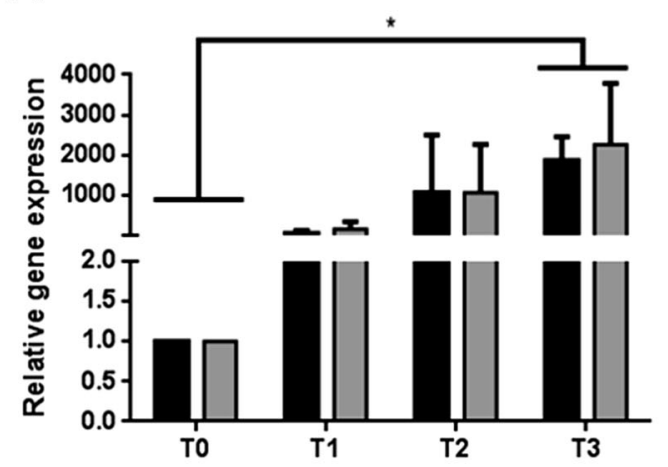

(b)

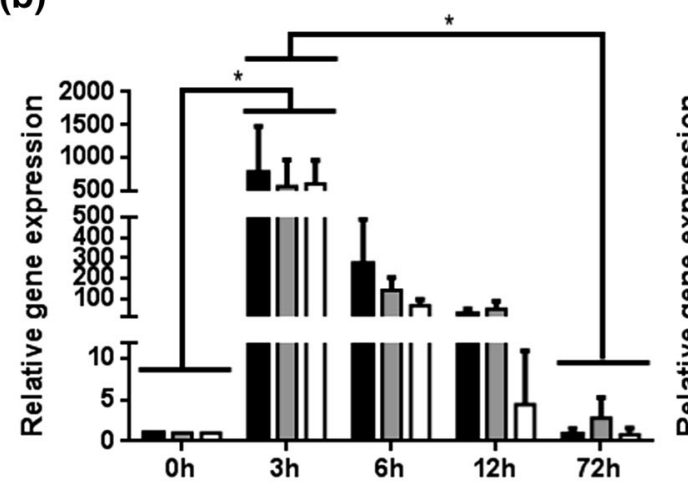

CD45
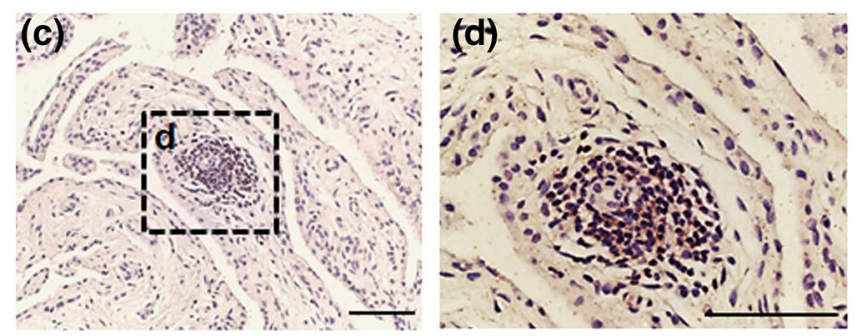

Fig. 6 In vitro and in vivo studies of GRP association with inflammatory events in osteoarthritis. a Gene expression of COX2 and MMP13 over 3 weeks of mineralizing treatment $(5.4 \mathrm{mM}$ calcium) in NHAC and HFLS (each week a set point, T0-T3). Values of gene expression are relative to the reference sample (T0) and set to 1 . Data are representative of three independent experiments. Two-way Anova and multiple comparisons were achieved with the Tukey's test. Statistical significance was defined as $P \leq 0.05\left(^{*}\right)$ and $P \leq 0.005$ (**). b Gene expression levels of COX2, MMP13 and

[37]. Interestingly, we also showed that synoviocytes were able to produce a mineralized ECM with up-regulation of $\mathrm{OC}$ and OPN, and down-regulation of vimentin, suggesting a possible contribution of synoviocytes to the production of BCPs in OA articular joint. BCPs have been shown to play an important role in the onset and progression of OA [5], and are considered to be early phenomena affecting the whole joint, occurring even before any evidence of
HFLS

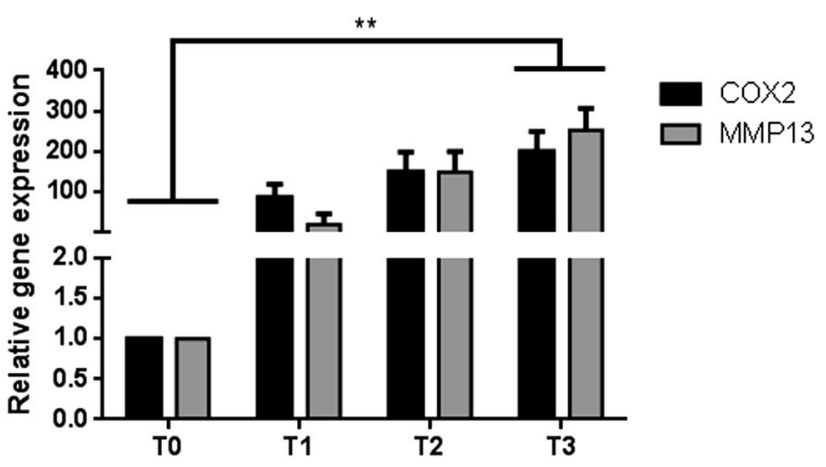

HFLS

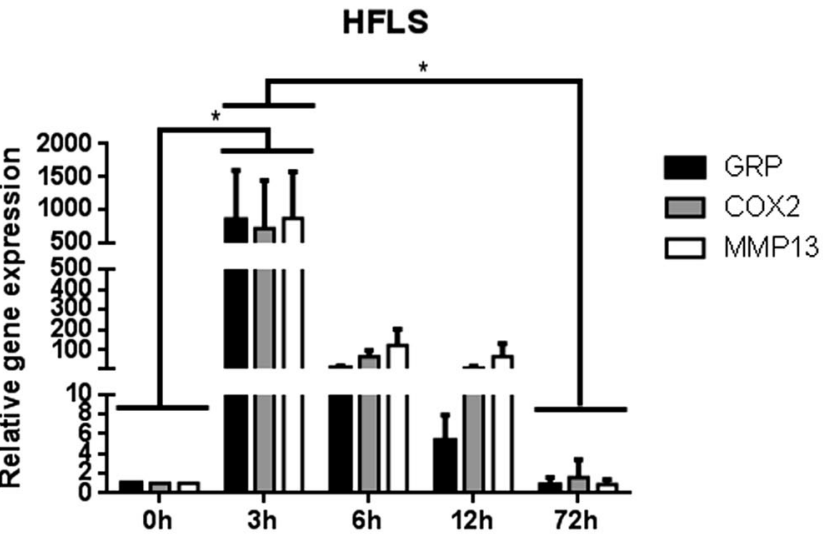

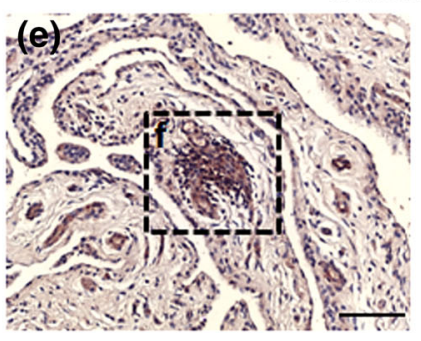

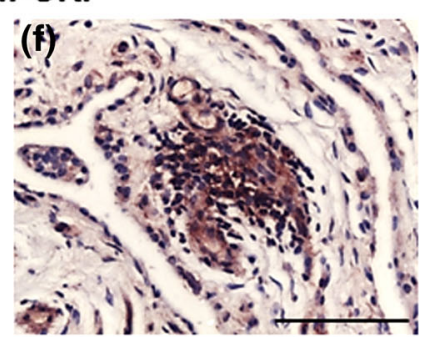

GRP in NHAC and HFLS cells, after 72-h inflammatory stimulation with $5 \mathrm{ng} / \mathrm{mL}$ IL-1 $\beta$. Values are relative to the reference sample $(0 \mathrm{~h})$. Data are representative of three independent experiments. Two-way Anova and multiple comparisons were achieved with the Tukey's test. Statistical significance was defined as $P \leq 0.05(*)$. c-f Immunodetection of CD45, showing leucocyte infiltration sites (c and d) and total GRP (e and $\mathbf{f}$, CTerm-GRP antibody) in consecutive sections of osteoarthritic synovial membrane samples. Counterstaining with HE; sale bar represents $100 \mu \mathrm{m}$

cartilage breakdown [4]. BCPs have been found in the synovial fluid, synovial membrane and cartilage from OA patients $[4,6,7]$, and are currently considered a damageassociated molecular pattern (DAMP). The underlying mechanism is thought to be the signaling to the immune system a state of stress [8], and potentially contributing to OA-associated inflammation through stimulation of articular cells [6, 7]. Besides their effect on synoviocyte 
(a)
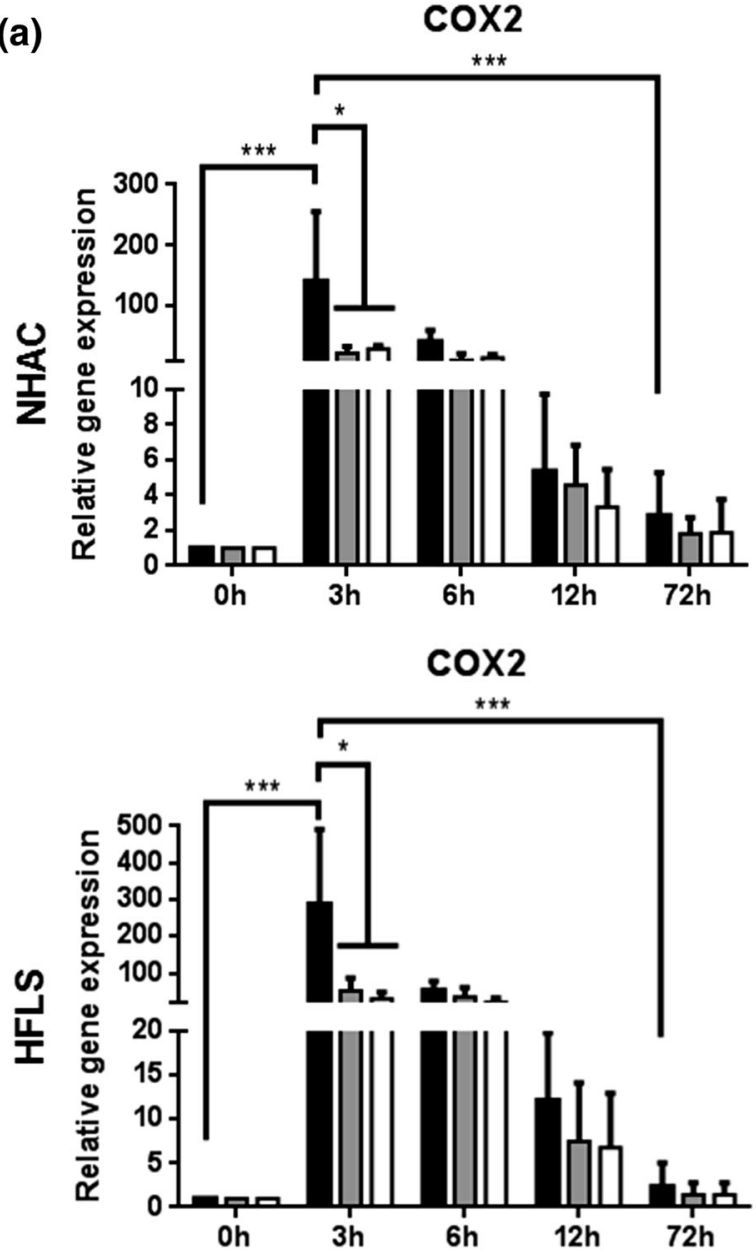

(b)

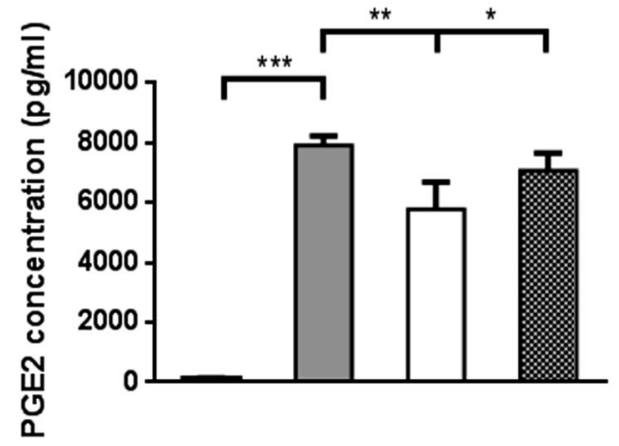

NHAC

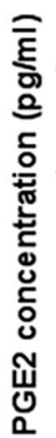

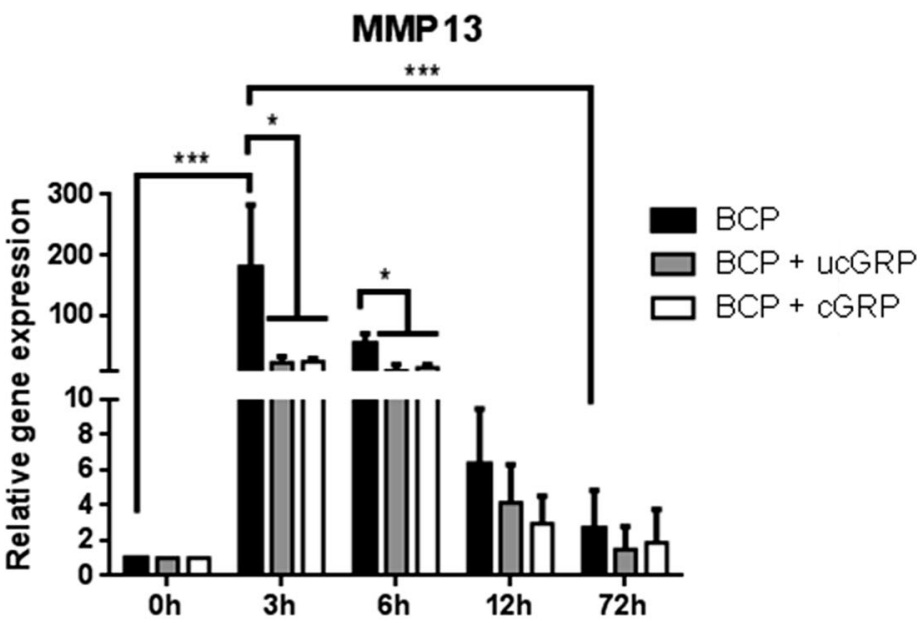

MMP 13

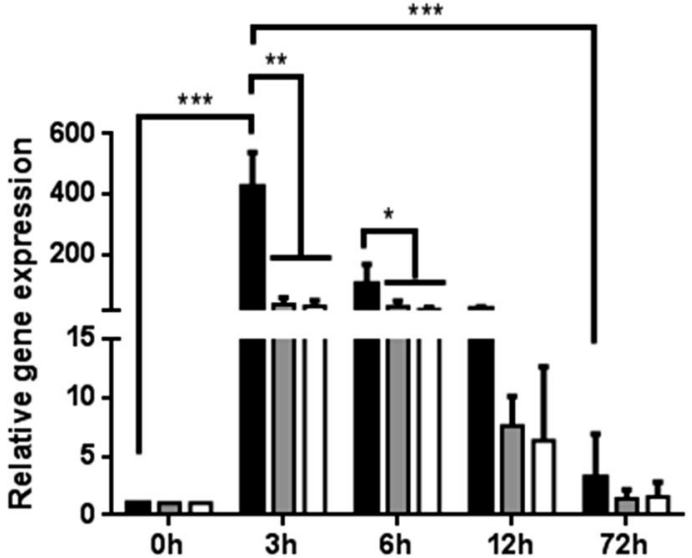

HFLS

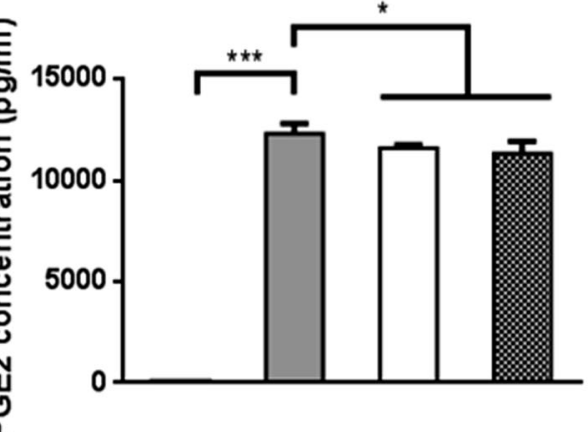

Control

$\mathrm{BCP}$

$B C P+U C G R P$

$B G P+C G R P$

Fig. 7 Effect of GRP in the inflammatory process promoted by the addition of BCP crystals to articular cells. a Gene expression of COX2 and MMP13 in NHAC and HFLS cells supplemented for $72 \mathrm{~h}$ with BCP crystals (BCP) or BCPs coated with ucGRP $(\mathrm{BCP}+\mathrm{ucGRP})$ or cGRP $(\mathrm{BCP}+\mathrm{cGRP})$. Values are relative to the reference sample (untreated cells $0 \mathrm{~h}$ ). Data are representative of three independent experiments. Two-way Anova and multiple

proliferation, along with production of inflammatory cytokines, MMPs and prostaglandins, BCP crystals also induce articular chondrocytes to produce prodegradative comparisons were achieved with the Tukey's test. Statistical significance was defined as $P \leq 0.05(*), P \leq 0.005(* *)$ and $P \leq 0.0005$ (***). b PGE2 accumulation in NHAC and HFLS conditioned media of cells treated for $72 \mathrm{~h}$ as described in a. Control corresponds to culture media of non-treated cells. Ordinary one-way ANOVA was performed. Statistical significance was defined as $P \leq 0.05\left(^{*}\right)$, $P \leq 0.005(* *)$ and $P \leq 0.0005(* * *)$

soluble factors such as nitric oxide and to undergo apoptosis [5, 7, 8]. Production of MMPs and chondrocyte apoptosis contributes to cartilage destruction, while 
(a)
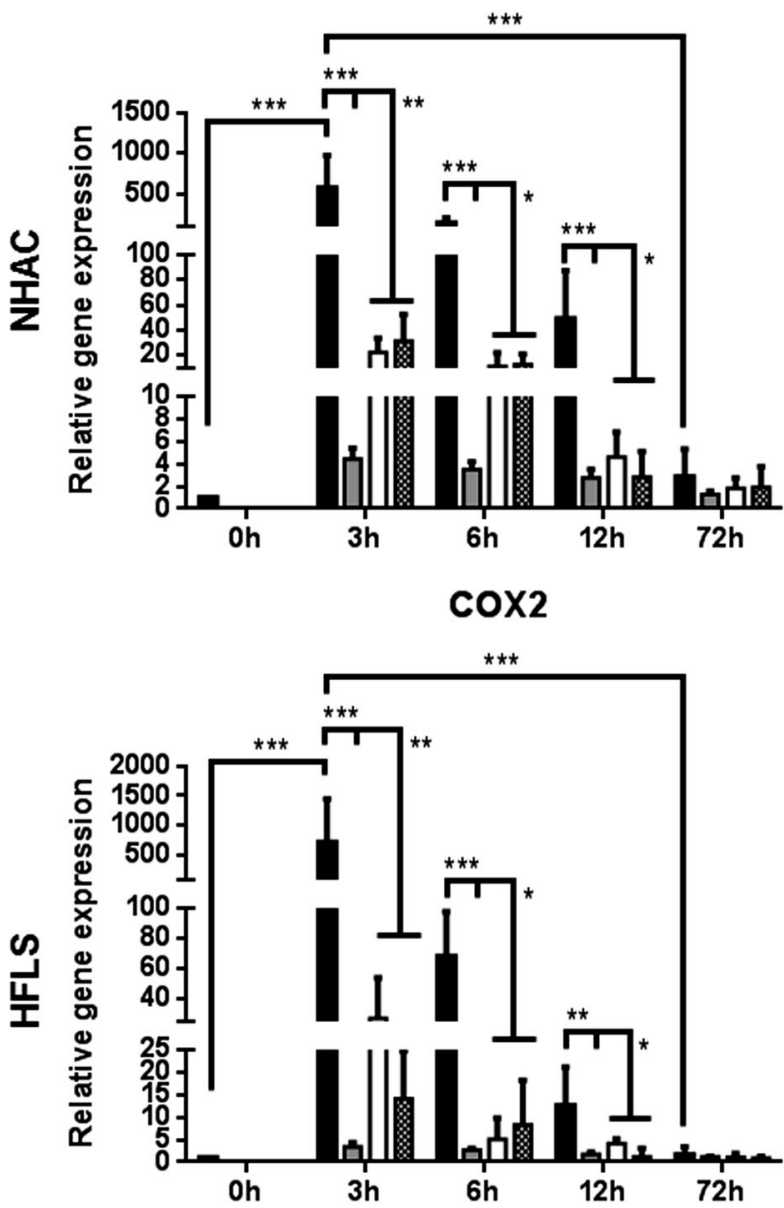

MMP 13
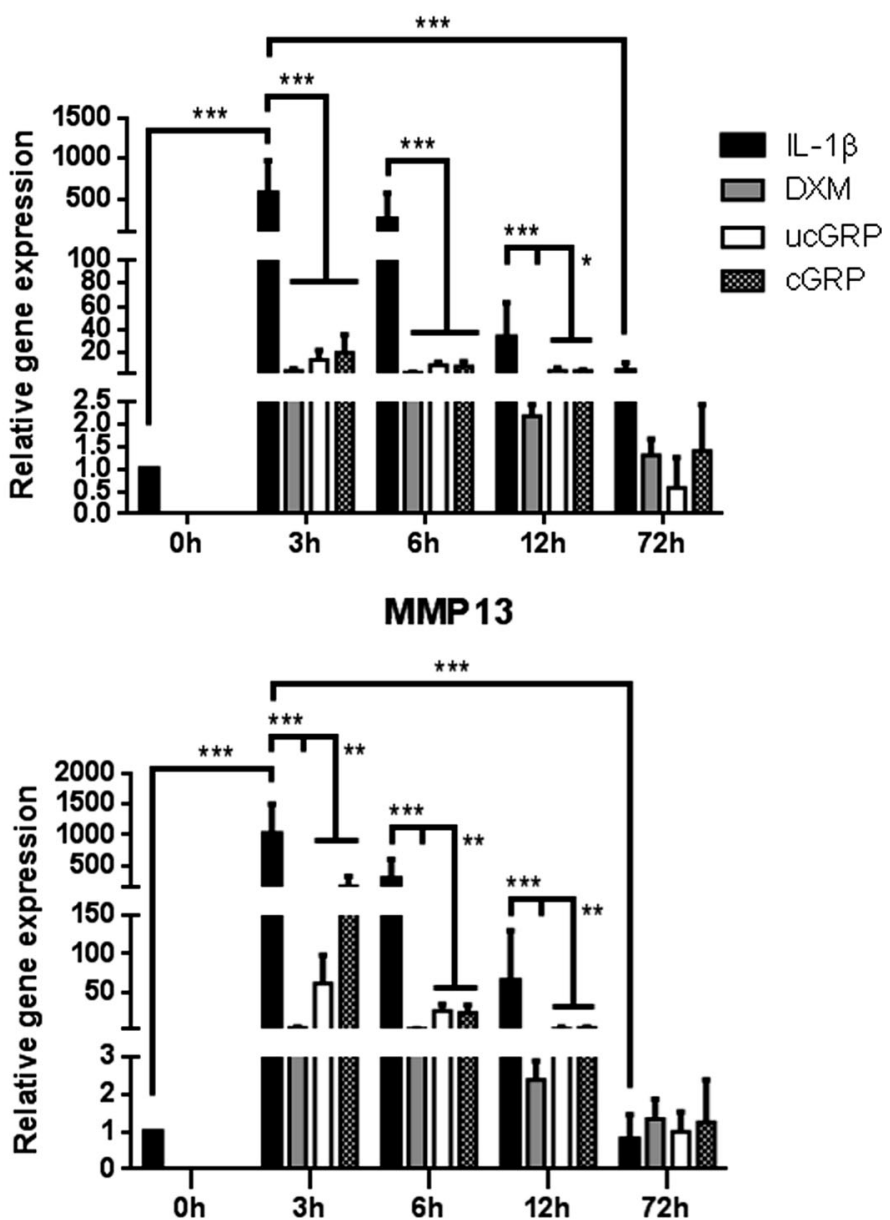

HFLS

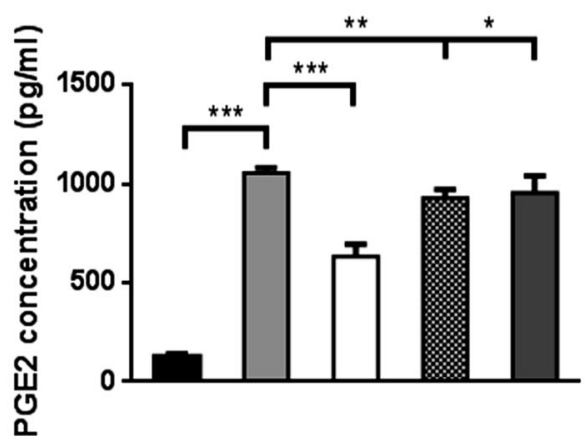

Fig. 8 Effect of GRP in chondrocytes and synoviocytes under in vitro inflammatory conditions mimicking osteoarthritis. a Gene expression of COX2 and MMP13 in NHAC and HFLS cells pretreated with $500 \mathrm{ng} / \mathrm{mL}$ of ucGRP or cGRP or $2 \mu \mathrm{M}$ dexamethasone (DXM) followed by IL-1 $\beta$ stimulation $(5 \mathrm{ng} / \mathrm{mL})$ during $72 \mathrm{~h}$. Cells untreated with GRP or DMX were also analyzed (IL-1 $\beta$ ). Control corresponds to cells grown in advanced DMEM only. Values are relative to the reference sample $(0 \mathrm{~h})$. Data are representative of three

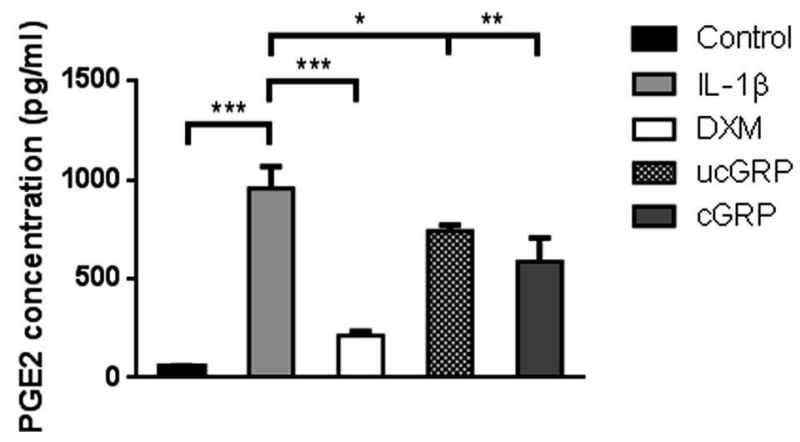

independent experiments. Two-way Anova and multiple comparisons were achieved with the Tukey's test. Statistical significance was defined as $P \leq 0.05$ (*), $P \leq 0.005$ (**) and $P \leq 0.0005$ (***). b PGE2 accumulation in cell media of NHAC and HFLS treated for $24 \mathrm{~h}$ as described in (a). Control corresponds to culture media of nontreated cells. Ordinary one-way ANOVA was performed. Statistical significance was defined as $P \leq 0.05(*), P \leq 0.005(* *)$ and $P \leq 0.0005(* * *)$ 
cartilage degradation products drive inflammatory events in a pathological mineralization-inflammation tissue degradation cycle $[5,7]$. To unveil the role of GRP in the mineralization-inflammation processes associated with OA, we decided to investigate the effect of GRP-induced modulation of inflammatory conditions triggered by a mineralization stimulus. COX2 and MMP13 up-regulation was observed during mineralization in chondrocytes and synoviocytes and confirmed that calcification can stimulate proinflammatory signaling that parallels cell differentiation, whereas calcification is also accompanied by an upregulation of GRP expression. These results reinforce the concept that also other cells of the joint, including fibroblast-like synoviocytes and chondrocytes, directly contribute to the innate immune activation and cytokine production in OA [8]. Moreover, the concomitant increase in GRP expression with inflammation, triggered by mineralization conditions, indicates a calcium-mediated role for GRP in the inflammatory processes. However, our experiments also showed increased GRP expression after inducing inflammation with IL-1 $\beta$, with a highly similar pattern to the inflammatory markers COX2 and MMP13. These results suggest that the involvement of GRP in inflammatory-mediated processes might not be exclusively mediated by mineralization events, opening new perspectives for GRP as a novel cross-talk factor linking calcification and inflammation processes occurring in articular cells that should become highly relevant for the study of OA development and progression.

As previously reported, GRP is able to bind BCP crystals in vitro and the calcification inhibitory function of GRP might be through modulation of crystal formation and/or growth [21]. Moreover, BCPs have been suggested to have a direct pathogenic role in OA, driving synovial inflammation and cartilage degradation [5]. Based on these facts, we decided to further investigate the potential role of GRP in the inflammatory response mediated by BCPs in the articular cell system. Our results clearly demonstrate that coating BCP crystals with GRP reduces its proinflammatory effect, protecting cells from the increased expression of MMP13 and PGE2 production. It has been proposed that calcium-containing crystals may activate articular cells by either leading to an increase in intracellular calcium levels after crystal endocytosis or phagocytosis, with consequent intralysosomal crystal dissolution, through direct crystalcell membrane interaction, that may occur via electrostatic bonds with the naked crystal surface, or by membrane receptor stimulation with naked or protein-coated crystals [37]. Although the mechanisms behind a GRP-BCP mediated anti-inflammatory effect in articular cells are currently unknown, we speculate that GRP binding to BCP will probably interfere with crystal-cell membrane interaction, thus modulating the production of proinflammatory mediators. It is interesting to note that, compared with naked hydroxyapatite crystals, fetuin-A-containing calciprotein particles (CPP), well known for their role in the prevention of uncontrolled mineralization, were recently reported to decrease cytokine production in macrophages [38]. Moreover, serum-derived CPP have been shown to produce a higher protective effect than synthetic CPP in macrophage activation [38], probably reflecting the inhibitory activity of other serum components, such as GRP. We have recently shown an association between GRP, fetuin-A and MGP at sites of aortic valves calcification, and proposed that the calcification inhibitory function of GRP may occur constitutively via this potent inhibitory system formed by proteins with strong calcium phosphate binding capacity [21]. Furthermore, pre-treatment of chondrocytes and synoviocytes with GRP followed by IL$1 \beta$ stimulation mirrored the anti-inflammatory effect observed with GRP-coated BCPs. This is consistent with an anti-inflammatory role by down-regulation of cytokines and MMPs production, in some cases at levels comparable to DXM. Interestingly, the anti-inflammatory-mediated effect of GRP was apparently independent of its $\gamma$-carboxylation status, suggesting additional functions for undercarboxylated GRP. Although undercarboxylated VKDPs are generally regarded as non-functional and related to pathological states [32, 39], decreased $\gamma$-carboxylation of OC has been implicated in the regulation of energy metabolism, with novel metabolic roles [40]. This area is still under debate, however, and whether carboxylated or uncarboxylated osteocalcin acts as the active hormone in energy metabolism remains to be clarified. Moreover, in the past decade, vitamin $\mathrm{K}$ biological functions other than acting as a coenzyme of GGCX have been proposed, namely the anti-inflammatory effect of vitamin K2 through suppression of the NF-kB pathway with a dual pro-anabolic and anti-catabolic activity in bone [41]. In fact, inappropriate regulation of anti-catabolic activity in bone has been shown as one of the major causes of setting an inflammatory state in both OA and rheumatoid arthritis [42]. Although we have shown in this work that GRP is associated to inflammation in osteoarthritic synovial membrane undergoing synovitis, a process characterized by lymphocytes and plasma cells infiltration [43], its involvement in immune cells inflammatory responses is presently unclear. Also, additional characterization of the anti-inflammatory activity of GRP and correlation with $\gamma$ carboxylation status is necessary to further unveil the molecular pathways involved.

Overall, we propose that in a context of OA with induced cell differentiation and ECM calcification, the increased expression of VKDPs such as GRP and MGP might function to counteract calcification. However, system overload could lead to hampered $\gamma$-carboxylation 
capacity resulting in increased levels of undercarboxylated GRP, which might contribute to control the levels of inflammatory mediators through still unknown mechanisms, and thereby protecting the joint structures from damage. Moreover, our results have shown that the effects of GRP in both calcification and inflammation processes were similar in control and OA-derived cell cultures, indicating that GRP can exert its function as calcification inhibitor and mediator of inflammation at different $\mathrm{OA}$ stages. Therefore, it is a potential candidate for therapeutics in OA, acting at both calcification and inflammation processes.

Acknowledgments This work was funded by projects PTDC/SAUORG/112832/2009, PTDC/SAU-ORG/117266/2010 and PTDC/BIMMEC/1168/2012, and also through Project UID/Multi/04326/2013, all from the Portuguese Science and Technology Foundation (FCT). S. Cavaco, C. S. B. Viegas and M. S. Rafael were the recipients of the FCT fellowships SFRH/BD/60867/2009, SFRH/BPD/70277/2010 and SFRH/BPD/89188/2012, respectively. Authors acknowledge the Orthopedics and Traumatology Service, Algarve Medical Centre (CHAlgarve), Faro, for providing the biological samples used in this study, and to Rheumatologic and Orthopedic Services of CHUAC for their help in obtaining cartilage samples. CIBER-BBN is a Spanish initiative from ISCIII.

\section{References}

1. Egloff C, Hügle T, Valderrabano V (2012) Biomechanics and pathomechanisms of osteoarthritis. Eur J Med Sci 142:w13583

2. Abramson SB, Attur M (2009) Developments in the scientific understanding of osteoarthritis. Arthritis Res Ther 11:227-235

3. Blanco FJ (2014) Osteoarthritis: something is moving. Reumatol Clin 10:4-5

4. Fuerst M, Bertrand J, Lammers L, Dreier R, Echtermeyer F, Nitschke Y, Nitschke Y, Rutsch F, Schäfer FK, Niggemeyer O, Steinhagen J, Lohmann CH, Pap T, Rüther W (2009) Calcification of articular cartilage in human osteoarthritis. Arthritis Rheum 60:2694-2703

5. Rosenthal AK (2011) Crystals, inflammation, and osteoarthritis. Curr Opin Rheumatol 23:170-173

6. Hernandez-Santana A, Yavorskyy A, Loughran ST, McCarthy GM, McMahon GP (2011) New approaches in the detection of calcium-containing microcrystals in synovial fluid. Bioanalysis 3:1085-1091

7. Liu YZ, Jackson AP, Cosgrove SD (2009) Contribution of calcium-containing crystals to cartilage degradation and synovial inflammation in osteoarthritis. Osteoarth Cartil 17:1333-1340

8. Sokolove J, Lepus CM (2013) Role of inflammation in the pathogenesis of osteoarthritis: latest findings and interpretations. Ther Adv Musculoskel Dis 5:77-94

9. Kraus VB, Blanco F, Englund M, Karsdal MA, Lohmander LS (2015) Call for standardized definitions of osteoarthritis and risk stratification for clinical trials and clinical use. Osteoarth Cartil 23:1233-1241

10. Shroff RC, Shanahan CM (2007) The vascular biology of calcification. Semin Dial 20:103-109

11. Luo G, Ducy P, Mckee MD, Pinero GJ, Loyer E, Behringer RR, Karsenty G (1997) Spontaneous calcification of arteries and cartilage in mice lacking matrix Gla protein. Nature 386:78-81
12. Shea M, Booth SL, Massaro JM, Jacques PF, D'Agostinho RB, Dawson-Hughes B, Ordovas JM, O'Donnell CJ, Kathiresan S, Keaney JF Jr, Vasan RS, Benjamin EJ (2008) Vitamin K and vitamin D status: associations with inflammatory markers in the Framingham Offspring Study. Am J Epidemiol 167:313-320

13. Wallin R, Wajih N, Hutson SM (2008) VKORC1: a warfarinsensitive enzyme in vitamin $\mathrm{K}$ metabolism and biosynthesis of vitamin K-dependent blood coagulation factors. Vitam Horm 78:227-246

14. Misra D, Booth SL, Tolstykh I, Felson DT, Nevitt MC, Lewis CE, Torner J, Neogi T (2013) Vitamin K deficiency is associated with incident knee osteoarthritis. Am J Med 126:243-248

15. Neogi T, Booth SL, Zhang YQ, Jacques PF, Terkeltaub R, Aliabadi P, Felson DT (2006) Low vitamin K status is associated with osteoarthritis in the hand and knee. Arthritis Rheum 54:1255-1261

16. Naito K, Watari T, Obayashi O, Katsube S, Nagaoka I, Kaneko K (2011) Relationship between serum undercarboxylated osteocalcin and hyaluronan levels in patients with bilateral knee osteoarthritis. Int J Mol Med 29:756-760

17. Silaghi C, Fodor D, Cristea V, Crãciun AM (2012) Synovial and serum levels of uncarboxylated matrix Gla-protein (ucMGP) in patients with arthritis. Clin Chem Lab Med 50:125-128

18. Viegas CSB, Simes DC, Laizè V, Williamson MK, Price PA, Cancela ML (2008) Gla-rich Protein (GRP), a new vitamin $\mathrm{K}$-dependent protein identified from sturgeon cartilage and highly conserved in vertebrates. J Biol Chem 283:36655-36664

19. Viegas CSB, Cavaco S, Neves PL, Ferreira A, João A, Williamson MK, Price PA, Cancela ML, Simes DC (2009) Gla-rich protein (GRP) is a novel vitamin $\mathrm{K}$ dependent protein present in serum and accumulated at sites of pathological calcifications. Am J Pathol 175:2288-2298

20. Viegas CSB, Herfs M, Rafael MS, Enriquez JL, Teixeira A, Luís I, van 't Hoofd C, João A, Maria VL, Cavaco S, Ferreira A, Serra M, Theuwissen E, Vermeer C, Simes, DC (2014) Gla-rich protein is a potential new vitamin $\mathrm{K}$ target in cancer: Evidences for a direct GRP-mineral interaction. Biomed Res Int. doi:10.1155/ 2014/340216

21. Viegas CSB, Rafael M, Enriquez JL, Teixeira A, Vitorino R, Luís IM, Costa RM, Santos S, Cavaco S, Neves J, Willems B, Vermeer C, Simes DC (2015) Gla-rich protein (GRP) acts as a calcification inhibitor in the human cardiovascular system. Arterioscler Thromb Vasc Biol 35:399-408

22. Eitzinger N, Surmann-Schmitt C, Bosl M, Schett G, Engelke K, Hess A, von der Mark K, Stock M (2012) Ucma is not necessary for normal development of the mouse skeleton. Bone 50:670-680

23. Neacsu CD, Grosch M, Tejada M, Winterpacht A, Paulsson M, Wagener R, Tagariello A (2011) Ucmaa (Grp-2) is required for zebrafish skeletal development. Evidence for a functional role of its glutamate $\gamma$-carboxylation. Matrix Biol 30:369-378

24. Surmann-Schmitt C, Dietz U, Kireva T, Adam N, Park J, Tagariello A, Onnerfjord P, Heinegård D, Schlötzer-Schrehardt U, Deutzmann R, von der Mark K, Stock M (2008) Ucma, a novel secreted cartilage-specific protein with implications in osteogenesis. J Biol Chem 283:7082-7093

25. Tagariello A, Luther J, Streiter M, Didt-Koziel L, Wuelling M, Surmann-Schmitt C, Stock M, Adam N, Vortkamp A, Winterpacht A (2008) Ucma-A novel secreted factor represents a highly specific marker for distal chondrocytes. Matrix Biol 27:3-11

26. Lee YJ, Park SY, Lee SJ, Boo YC, Choi JY, Kim JE (2015) Ucma, a direct transcriptional target of Runx2 and Osterix, promotes osteoblast differentiation and nodule formation. Osteoarth Cartil. doi:10.1016/j.joca.2015.03.035

27. Rafael MS, Cavaco S, Viegas CSB, Santos S, Ramos A, Willems B, Herfs M, Theuwissen E, Vermeer C, Simes DC (2014) Insights into the association of Gla-rich protein and osteoarthritis, novel 
splice variants and $\gamma$-carboxylation status. Mol Nutr Food Res. doi:10.1002/mnfr.201300941

28. Ortiz-Delgado JB, Simes DC, Viegas CSB, Schaff BJ, Sarasquete C, Cancela ML (2006) Cloning of matrix Gla protein in amarine cartilaginous fish, Prionace glauca: preferential protein accumulation in skeletal and vascular systems. Histochem Cell Biol 126:89-101

29. Burguera EF, Vela AA, Magalhães J, Meijide-Faílde R, Blanco FJ (2014) Effect of hydrogen sulfide sources on inflammation and catabolic markers on interleukin $1 \beta$-stimulated human articular chondrocytes. Osteoarth Cartil 22:1026-1035

30. Cillero PB, Martin M, Arenas J, Lopez-Armada MJ, Blanco FJ (2011) Effect of nitric oxide on mitochondrial activity of human synovial cells. B Musculoskelet Disord 12:1471-2474

31. Chomczynski P, Sacchi N (1987) Single-step method of RNA isolation by acid guanidinium thiocyanate phenol chloroform extraction. Anal Biochem 162:156-159

32. Schurgers LJ, Teunissen KJ, Knapen MH, Kwaijtaal M, van Diest R, Appels A, Reutelingsperger CP, Cleutjens JP, Vermeer C (2005) Novel conformation-specific antibodies against matrix gamma-carboxyglutamic acid (Gla) protein: undercarboxylated matrix Gla protein as marker for vascular calcification. Arterioscler Thromb Vasc Biol 25:1629-1633

33. Pombinho AR, LaizéV Molha DM, Marques SMP, Cancela ML (2004) Development of two bone-derived cell lines from the marine teleost Sparus aurata; evidence for extracellular matrix mineralization and cell-type-specific expression of matrix Gla protein and osteocalcin. Cell Tissue Res 315:393-406

34. McCarthy GM, Westfall P, Masuda I, Christopherson PA, Cheung HS, Mitchell PG (2001) Basic calcium phosphate crystals activate human osteoarthritic synovial fibroblasts and induce matrix metalloproteinase-13 (collagenase-3) in adult porcine articular chondrocytes.Ann Rheum Dis Aquat Organ 60:399-406
35. Nakatani S, Mano H, Ryanghyok IM, Shimizu J, Wada M (2006) Excess magnesium inhibits excess calcium-induced matrix-mineralization and production of matrix gla protein (MGP) by ATDC5 cells. Biochem Biophys Res Commun 348:1157-1162

36. Wallin R, Schurgers LJ, Loeser RF (2010) Biosynthesis of the vitamin K-dependent matrix Gla protein (MGP) in chondrocytes: a fetuin-MGP protein complex is assembled in vesicles shed from normal but not from osteoarthritic chondrocytes. Osteoarth Cartil 16:1096-1103

37. Ea HK, Nguyen C, Bazin D, Bianchi A, Jérôme G, Pascal R, Daudon M, Frédéric Lioté (2011) Articular cartilage calcification in osteoarthritis. Arthritis Rheum 63:10-18

38. Smith ER, Hanssen E, McMahon LP, Holt SG (2013) Fetuin-Acontaining calciprotein particles reduce mineral stress in the macrophage. PLoS One 8:e60904

39. Cranenburg EC, Schurgers LJ, Vermeer C (2007) Vitamin K: the coagulation vitamin that became omnipotent. Thromb Haemostasis $98: 120-125$

40. Zoch ML, Clemens TL, Riddle RC (2015) New insights into the biology of osteocalcin. Bone. doi:10.1016/j.bone.2015.05.046

41. Yamaguchi M, Weitzmann M (2010) Vitamin K2 stimulates osteoblastogenesis and suppresses osteoclastogenesis by suppressing NF- $\kappa \mathrm{B}$ activation. Int $\mathrm{J}$ Mol Med 27:3-14

42. Roman-Blas JA, Jimenez SA (2006) NF- $\kappa B$ as a potential therapeutic target in osteoarthritis and rheumatoid arthritis. Osteoarthritis Cartilage 14:839-848

43. Pobirci O, Bogdan F, Pobirci DD, Rosca E, Petcu CA (2011) The study of synovities with articular inflammatory liquid, through clinical-statistical, histological and immunohistochemical methods. Rom J Morphol Embryol 52:333-338 